\title{
Analysis of the Chemical State in Y-zeolite Pores by Positron Annihilation Lifetime Spectroscopy
}

\author{
Luca ChIARI, ${ }^{\dagger}$ Chihiro OHNuki, and Masanori FuJINAMI \\ Department of Applied Chemistry and Biotechnology, Chiba University, 1-33 Yayoi, Inage, Chiba 263-8522, Japan
}

\begin{abstract}
The chemical state of the active sites in the pores of zeolites is known to greatly affect their chemical and catalytic properties, e.g. the presence of Brønsted acid sites enhances their action as polar adsorbents. Ortho-positronium diffusion in the pore network has been widely used to clarify the zeolite structure, but its interaction with acid centers under different environments remains unclear. Here, a systematic study on Y-zeolites over a wide range of Si/Al ratios in the absence and presence of water in the framework was carried out using positron annihilation lifetime spectroscopy. The acidity of the pores was found to significantly inhibit positronium formation and annihilation within the crystalline micropore network in the dehydrated condition, highlighting a strong positronium oxidizing action of the acid centers. Upon water adsorption, the interaction of the acid sites with the water molecules enabled the recovery of positronium formation in the hydrophilic low-silica samples.
\end{abstract}

Keywords Zeolite, acidity, water adsorption, positron annihilation lifetime spectroscopy

(Received November 20, 2020; Accepted December 30, 2020; Advance Publication Released Online by J-STAGE January 8, 2021)

\section{Introduction}

Zeolites are porous materials with a three-dimensional framework made of corner-sharing $\left(\mathrm{SiO}_{4}\right)^{4-}$ and $\left(\mathrm{AlO}_{4}\right)^{5-}$ tetrahedral constituents and embody regular channels and cages. ${ }^{1}$ They are widely used as catalysts by taking advantage of the molecular sieve effect of the sub-nanosized pores and the active sites in the pores. $^{2}$ The portion of $\mathrm{Al}$ within the aluminosilicate skeleton is known to greatly affect their chemical properties such as the catalytic activity, chemical affinity, hydrophobicity, chemical resistance and acid strength. ${ }^{3}$ Their surface property changes from hydrophilic to hydrophobic as the Si/Al ratio increases, because they have less binding sites and hence lower sorption capacity. ${ }^{4}$ In order to elucidate the catalytic reaction mechanism of zeolites, it is necessary to analyze the chemical state of the active sites in the pores.

Positronium (Ps), a metastable bound state of an electron and a positron, has been extensively used as a probe of (sub-) nanosized voids and pores in amorphous systems, ${ }^{5,6}$ such as glasses, ${ }^{7,8}$ polymers ${ }^{9,10}$ and also zeolites. ${ }^{11-13}$ Ortho-positronium $(o$-Ps) pick-off annihilation is affected by the presence of free volume: its lifetime reflects the void size, while its formation probability depends on the amount of free volume and the chemical environment. ${ }^{14}$ It is also known that the presence of electron-withdrawing functional groups shortens the Ps lifetime and reduces the Ps formation probability due to the chemical reaction with Ps. ${ }^{15,16}$

Acid sites are commonly present throughout the zeolite pore networks since they are related to the number of framework $\mathrm{Al}$ atoms. Numerous experimental and theoretical studies investigated

$\dagger$ To whom correspondence should be addressed.

E-mail: luca.chiari@chiba-u.jp the effect of these centers on the chemical and catalytic properties of zeolites. ${ }^{17-28}$ In general, the catalytic activity was found to increase and the action as a polar adsorbent (hydrophilicity) became stronger with the number of Brønsted acid sites. The specific surface area, ${ }^{29-31}$ pore size distributions, ${ }^{30,32,33}$ crystallinity, ${ }^{30-34}$ and $\mathrm{Al}$ distribution within and outside the framework ${ }^{31,35-38}$ in numerous zeolites, including the Y zeolites that are the subject of the present study, have been extensively studied both through empirical measurements and modelling. As a result, the influence of these properties on the acid strength is well characterized. ${ }^{19,36,39,40}$

As $o$-Ps diffusion provides non-destructive insight into the surface chemical activity with higher sensitivity than other techniques ${ }^{41}$ it was naturally used to characterize the surface acidity. ${ }^{12,42-54}$ Those studies highlighted a potential Ps oxidizing effect of the acid sites that decreased the net amount of $o$-Ps formation. Nonetheless, the interaction of $o$-Ps with these acid centers remains relatively poorly understood as earlier measurements cover a rather limited range of $\mathrm{Si} / \mathrm{Al}$ ratios. ${ }^{46,50}$ To address this key aspect, here we investigated the effect of the change in concentration of Brønsted acid sites and hydration on Ps formation and annihilation in zeolites. Positron annihilation lifetime spectroscopy (PALS) measurements were carried out on FAU-type Y zeolites with a unified skeleton structure but over a wide range of $\mathrm{Si} / \mathrm{Al}$ ratios. Based on the observed trends in the Ps lifetime and intensity, we determined the factors that influence Ps formation, diffusion, and annihilation and qualitatively evaluated the chemical state of the pores.

\section{Experimental}

Y-type zeolites have a three-dimensional framework with 12 -membered rings and pore size of $0.74 \times 0.74 \mathrm{~nm}$. Super- 

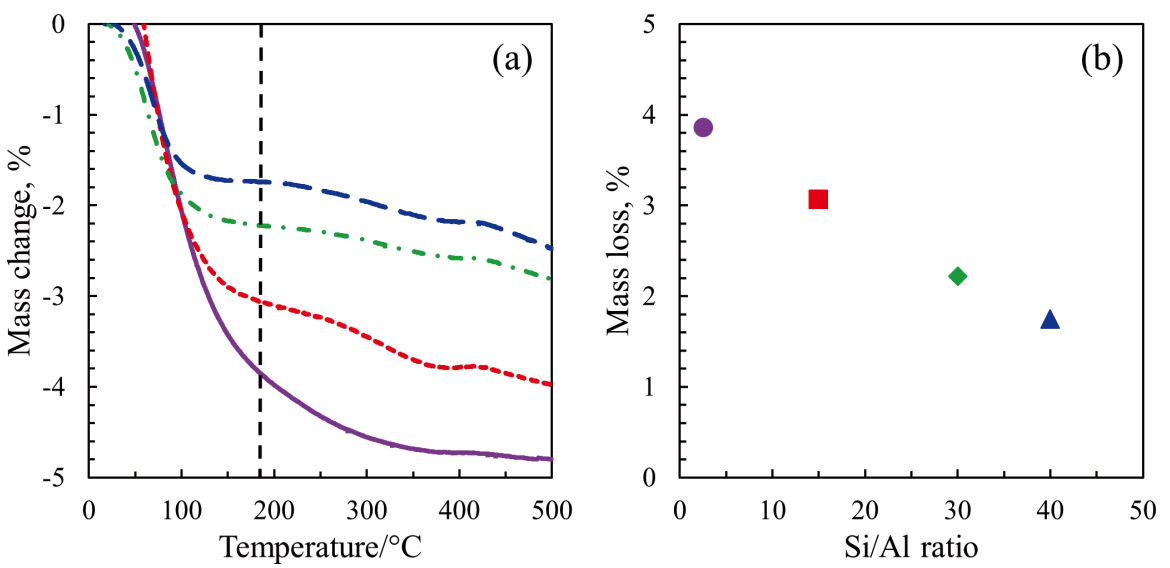

Fig. 1 (a) TGA curves of the relative change in weight as a function of temperature for each $\mathrm{Si} / \mathrm{Al}$ ratio: (-) 2.6, (-..--) 15, (---) 30, (---) 40. The vertical dashed line indicates the dehydration treatment temperature of $185^{\circ} \mathrm{C}$. (b) Dependence of the relative mass loss on the $\mathrm{Si} / \mathrm{Al}$ ratio from the TGA results at $185^{\circ} \mathrm{C}$.

cage structures with a diameter of $1.3 \mathrm{~nm}$ are also present. $\mathrm{Y}$ zeolites with $\mathrm{H}^{+}$counterions having $\mathrm{SiO}_{2} / \mathrm{Al}_{2} \mathrm{O}_{3}$ mol ratios of 2.6, 15, 30 and 40 were investigated in this study. Zeolite powder obtained from Alfa Aesar was molded into cylindrical pellets of $10 \mathrm{~mm}$ diameter and $2 \mathrm{~mm}$ thickness using a hydraulic press $(11 \mathrm{MPa})$. Based on earlier work, ${ }^{34}$ the samples were dehydrated in vacuum at $185^{\circ} \mathrm{C}$ for $2 \mathrm{~h}$ to remove any moisture absorbed in the zeolites during the preparation process. The samples were transported in an evacuated glass vial into a glovebox filled with Ar gas to avoid exposure of the zeolites to the atmospheric humidity. Inside the glovebox, a ${ }^{22} \mathrm{Na}$ positron source (activity $1.1 \mathrm{MBq}$ ) enclosed in Kapton films was sandwiched in between two identical zeolite samples for the positron lifetime measurements. The sample and source assembly was enclosed in a thermally sealed polyethylene bag together with a silica gel desiccant, an oxygen scavenger and an oxygen indicator tablet to ensure no exposure of the zeolites to the moisture in the atmosphere. After taking the bag out of the glovebox, PALS measurements were first conducted in this dehydrated condition (Ar atmosphere). After that, the sample + source assembly was removed from the bag and PALS measurements were performed in the atmosphere every $7 \mathrm{~h}$ (average time required to measure one lifetime spectrum) to observe the time change in the lifetime as the zeolites were adsorbing the moisture from the air.

For the positron lifetime measurements, we used a digital positron lifetime spectrometer consisting of two photomultiplier tubes coupled to $\mathrm{BaF}_{2}$ scintillators connected to a APV8702 time analysis module by TechnoAP Co. The time resolution of the spectrometer was $\sim 180 \mathrm{ps}$. The PALS spectra were measured until at least 2 million counts were accumulated in each spectrum to achieve enough statistical accuracy. The lifetime spectra were analyzed using the software PALSfit ${ }^{55}$ by least-squares fitting with the sum of exponential decay functions. The spectra were fitted with four lifetime components. Based on previous PALS studies of Y zeolites,${ }^{56}$ the origin of these lifetimes was ascribed as follows. The first component $\left(\tau_{1} \approx\right.$ $0.2 \mathrm{~ns}$ ) corresponds to para-Ps annihilation and positron selfannihilation, while the second component $\left(\tau_{2} \approx 0.5 \mathrm{~ns}\right)$ is from trapped positron annihilation. The third $\left(\tau_{3} \approx 2-5 \mathrm{~ns}\right)$ and fourth $\left(\tau_{4} \approx 20-50 \mathrm{~ns}\right)$ components arise from $o$-Ps pick-off annihilation in the crystalline micropore network and $o$-Ps annihilation in internal channels or intercrystalline voids, respectively. $o$-Ps pick-off annihilation is a porosimetric probe which reflects the adsorption or filling of the pores. In conjunction with the semi-empirical Tao-Eldrup model, ${ }^{57,58}$ from the measured lifetime value $\tau_{3}$ one can estimate the pore size. Since the fourth component stems, at least in part, from "almost free" $o$-Ps annihilation, it is not directly related to the size of cavities. The total $o$-Ps intensity is given by the sum of the relative intensities of the third and fourth components $\left(I_{3}+I_{4}\right)$ and corresponds to the fraction of positrons that annihilate as $o$-Ps in the cavities and bulk. In the presence of electron acceptors or unpaired electrons in the pores, $o$-Ps is quenched by chemical reactions or spin conversion and becomes a chemical probe of surface and catalysis.

Thermal gravimetric analysis (TGA) was conducted to measure the adsorbed water content in the as-prepared zeolites. A thermogravimetry/differential thermal analyser from Rigaku (Thermo plus EVO2 TG-DTA TG8120) was used. The zeolite powder was loaded as purchased and dynamic thermogravimetry was carried out from room temperature up to $500^{\circ} \mathrm{C}$ under a continuous nitrogen flow and a heating rate of $10^{\circ} \mathrm{C} / \mathrm{min}$.

\section{Results and Discussion}

Systematic structural characterization of $\mathrm{Y}$ zeolites was carried out in detail in earlier studies (see Introduction and references therein). Hence, here we simply measured the adsorbed content in the present samples by TGA because this depends on the specific environment history to which the zeolites were exposed. Figure 1(a) shows the relative mass change as a function of temperature for each $\mathrm{Si} / \mathrm{Al}$ ratio. The mass loss with an endothermic effect in the temperature range of $100-200^{\circ} \mathrm{C}$ was mostly due to the desorption of loosely bound water from the zeolite. Some of the samples exhibited additional mass loss even at higher temperatures, which may be attributed to the desorption of bonded water in the pores. Note that the zeolites were dehydrated at $185^{\circ} \mathrm{C}$ for an extended period of time to ensure that most of the adsorbed water content had desorbed even at this temperature. The dependence of the relative mass loss at $185^{\circ} \mathrm{C}$ on the $\mathrm{Si} / \mathrm{Al}$ ratio is shown in Fig. 1(b). The smaller the $\mathrm{Si} / \mathrm{Al}$ ratio, the larger was the mass loss, i.e. the adsorbed water content, which means that the zeolites were more hydrophilic. This trend is consistent with the known 


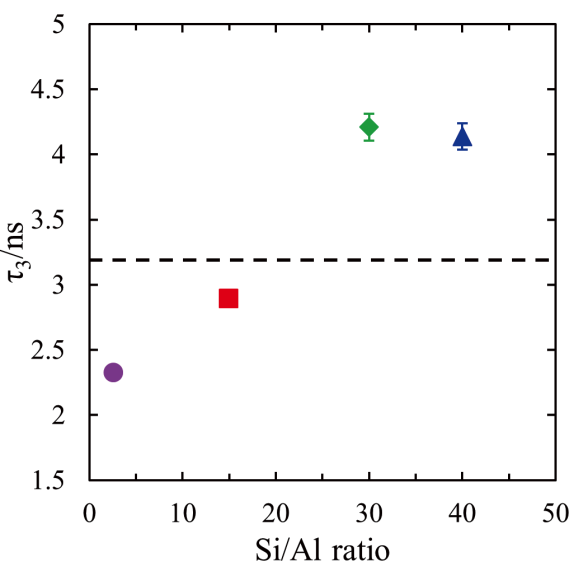

Fig. $2 o$-Ps pick-off lifetime $\tau_{3}$ in the dehydrated state as a function of the $\mathrm{Si} / \mathrm{Al}$ ratio. The dashed line indicates the lifetime value calculated with the Tao-Eldrup model from the known pore size.

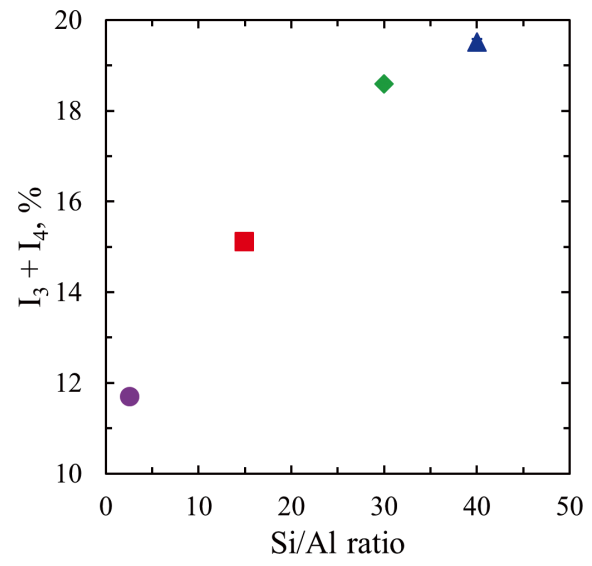

Fig. 3 Total $o$-Ps intensity $I_{3}+I_{4}$ in the dehydrated state as a function of the $\mathrm{Si} / \mathrm{Al}$ ratio.
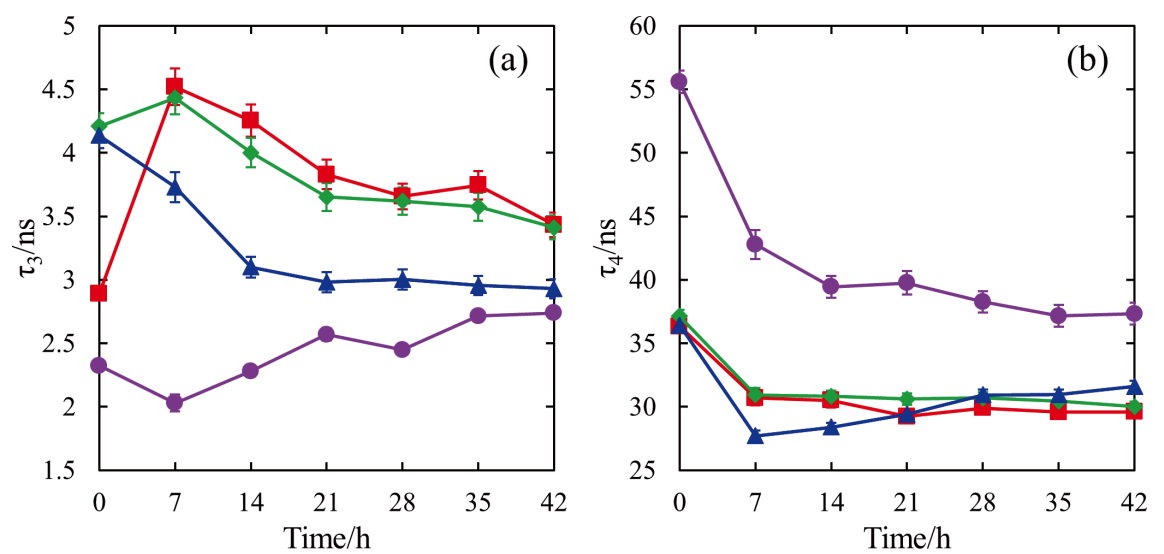

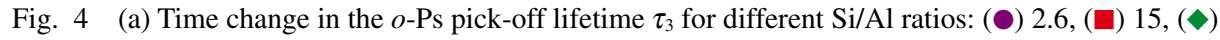
30, (४) 40. Time 0 corresponds to the dehydrated state and thereafter the time elapsed since the exposure to the atmospheric moisture. (b) Same as (a) but for the longest $o$-Ps lifetime $\tau_{4}$.

increasing water adsorption capacity of $\mathrm{Y}$ zeolites at lower $\mathrm{Si} / \mathrm{Al}$ ratios..$^{56}$

Figure 2 shows the $o$-Ps pick-off lifetime $\tau_{3}$ measured in the dehydrated state as a function of the $\mathrm{Si} / \mathrm{Al}$ ratio. The lower this ratio, the shorter was the measured lifetime. This result is ascribed to the larger number of Brønsted acid sites present in the pores of the samples with lower $\mathrm{Si} / \mathrm{Al}$ ratio. The presence of more negative-charged $\left(\mathrm{AlO}_{4}\right)^{5-}$ units can increase the Ps pickoff annihilation rate and, therefore, reduce the lifetime. The lifetime of the sample with lowest $\mathrm{Si} / \mathrm{Al}$ ratio agrees well with earlier PALS measurements on low-silica Y zeolites. ${ }^{34}$ The lifetime value calculated using the Tao-Eldrup equation from the known diameter of the $\beta$-cage or sodalite cage $(0.66 \mathrm{~nm})$ is $\sim 2.5 \mathrm{~ns}$, whereas that corresponding to the aperture size of the $\alpha$-cage $(0.74 \mathrm{~nm})$ is $\sim 3.2 \mathrm{~ns}$. As shown in Fig. 2 , the measured lifetimes are slightly lower than this latter value for the samples with low Si/Al ratio, whereas they are higher for those with high $\mathrm{Si} / \mathrm{Al}$ ratio. This result suggests that this lifetime component stems from $o$-Ps diffusing through the micropore framework and undergoing pick-off annihilation around the $\alpha$-cage apertures, as supported by earlier work. ${ }^{34}$ Although $o$-Ps tends to diffuse and annihilate in larger spaces, given that the lifetime of the sample with $\mathrm{Si} / \mathrm{Al}$ ratio $=2.6$ is close to $2.5 \mathrm{~ns}$, it cannot be excluded that some $o$-Ps also annihilate in the $\beta$-cages. The scatter in the measured lifetimes at different $\mathrm{Si} / \mathrm{Al}$ ratios is simply an acidity effect, as explained above. We also note that the lifetimes of the samples with $\mathrm{Si} / \mathrm{Al}$ ratios of 30 and 40 are essentially identical. Several nuclear magnetic resonance (NMR) spectra of Y zeolites reported the number and distribution of $\mathrm{Al}^{31,35,38}$ atoms and showed that the proportion of pure framework $\mathrm{Al}$ (or Brønsted acid sites) diminishes at higher $\mathrm{Si} / \mathrm{Al}$ ratios, as in other zeolites. ${ }^{40,59}$ Hence, the "saturation" of the lifetime at higher $\mathrm{Si} / \mathrm{Al}$ ratios might be an effect of these extra-framework cations.

The total $o$-Ps intensity $I_{3}+I_{4}$ measured in the dehydrated state as a function of the $\mathrm{Si} / \mathrm{Al}$ ratio is exhibited in Fig. 3. The $o$-Ps formation ratio was almost constant at higher $\mathrm{Si} / \mathrm{Al}$ ratios, but drastically decreased as that ratio was reduced. According to the spur reaction model, ${ }^{60,61}$ Ps is formed by thermalized positrons binding to electrons from a group of active species in the spur generated by the positrons ionizing surrounding atoms in the thermalization process. The scavenging of positrons or the electrons present in the spur by competing reactions, such as solvation or ion recombination, affect the Ps formation. ${ }^{62}$ As the $\mathrm{Si} / \mathrm{Al}$ ratio decreases, the number of negatively-charged Brønsted acid sites that can trap positrons is increased. Hence, a smaller fraction of incident positrons is expected to form Ps. Moreover, 
if Ps is formed, Ps oxidation by these acid sites also strongly affects the amount of $o$-Ps annihilation. ${ }^{53}$ Both these effects result in the net suppression of the Ps pick-off component. These results confirm the role of Brønsted acid sites as inhibitors of Ps formation, which was suggested by previous studies, ${ }^{12,51}$ although over more limited $\mathrm{Si} / \mathrm{Al}$ ranges. In addition, we note that the "saturation" in the $o$-Ps intensity observed at higher $\mathrm{Si}$ / Al ratios might be an effect of the increase in extra-framework Al cations, as mentioned above for the $o$-Ps lifetime.

Figure 4 shows the time change in the $o$-Ps lifetimes $\tau_{3}$ and $\tau_{4}$ due to the water adsorption after exposure to the atmosphere for different $\mathrm{Si} / \mathrm{Al}$ ratios. The $o$-Ps pick-off lifetime $\tau_{3}$ in the samples with the lowest $\mathrm{Si} / \mathrm{Al}$ ratios of 2.6 and 15 somewhat increased after water adsorption, whereas the samples with the highest $\mathrm{Si} / \mathrm{Al}$ ratios of 30 and 40 exhibited a net reduction. This decrease can be ascribed to the water molecules adsorbed in the pore network, which hinder the Ps diffusion. As a result, Ps tends to annihilate at a faster rate and the lifetime is reduced This is highlighted by the data of the most hydrophilic sample $(\mathrm{Si} / \mathrm{Al}$ ratio $=2.6)$ displaying the shortest lifetime. The lifetime of all samples exhibited the largest variation in the first $\sim 14 \mathrm{~h}$ of

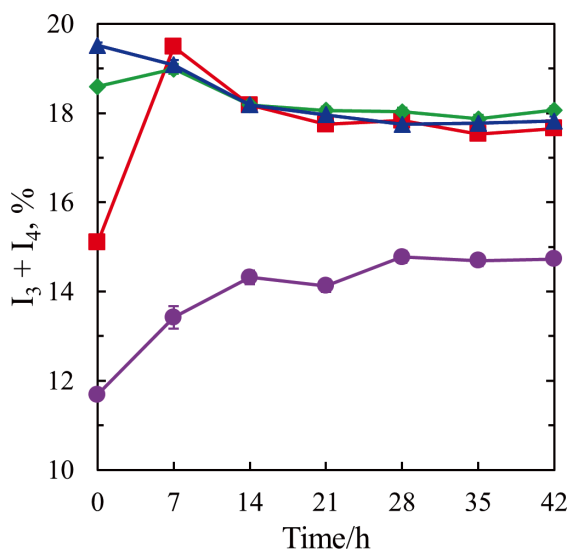

Fig. 5 Time change in the total $o$-Ps intensity $I_{3}+I_{4}$ for different

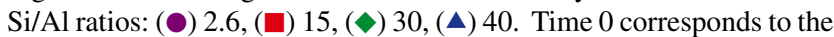
dehydrated state and thereafter the time elapsed since exposure to the atmospheric moisture. exposure to the atmosphere, but no significant change after that This result is in agreement with earlier time-dependent TGA measurements on other nanosilicate materials, ${ }^{63}$ which showed that the mass increases with exposure time owing to hydration in the interlayer spaces and reaches saturation after $10 \mathrm{~h}$ or so. We note a drastic increase in $\tau_{3}$ for the sample with the $\mathrm{Si} / \mathrm{Al}$ ratio of 15 immediately after exposure to the atmosphere $(7 \mathrm{~h})$, followed by a gradual decrease. Albeit much smaller in magnitude, a similar trend is also observed in the sample with the Si/Al ratio of 30. This behavior might reflect the fact that the lifetime reaches a maximum upon formation of a water monolayer, beyond which it gradually becomes shorter because of the increased pick-off annihilation rate due to multilayer adsorption and pore filling. ${ }^{64}$ The lifetime of all samples seems to converge towards $3.2 \mathrm{~ns}$ at the end of the measurement time span, which backs the $\alpha$-cage apertures as $o$-Ps annihilation sites.

Regarding the longest $o$-Ps lifetime $\tau_{4}$, in the dehydrated state it is the same ( $\sim 37 \mathrm{~ns})$ for the samples with the $\mathrm{Si} / \mathrm{Al}$ ratios of 15,30 and 40 , whereas it becomes much longer $(\sim 55 \mathrm{~ns})$ at the lowest $\mathrm{Si} / \mathrm{Al}$ ratio of 2.6. Now, if this lifetime component entirely originated from "almost free" $o$-Ps annihilating at grain boundaries, such a $\mathrm{Si} / \mathrm{Al}$ ratio dependence would not be expected. Therefore, the present results suggest that a contribution to this longest component from $o$-Ps annihilating in larger cavities or internal channels of the pore network, where the presence of Brønsted acid sites can affect the $o$-Ps annihilation, cannot be excluded. Note that the lifetime value calculated using the Tao-Eldrup equation from the known size $(1.4 \mathrm{~nm})$ of the supercage ( $\alpha$-cage) is $\sim 12 \mathrm{~ns}$, so that the fourth component must stem from annihilation in larger cavities. Upon water adsorption, $\tau_{4}$ becomes much shorter in all samples and may be ascribed to a process analogous to that observed for $\tau_{3}$, i.e. the suppression of the Ps diffusion in the micropore network by the water molecules.

The time change in the total $o$-Ps formation ratio upon water adsorption is given in Fig. 5. The $o$-Ps formation ratio rises in the samples with low $\mathrm{Si} / \mathrm{Al}$ ratios, while a slight decrease or no significant change is found in those with high $\mathrm{Si} / \mathrm{Al}$ ratios. The increase observed in the hydrophilic samples with low $\mathrm{Si} / \mathrm{Al}$ ratios is likely due to the presence of water molecules physisorbed at the Brønsted acid sites by hydrogen bonding. As these sites are no longer active, the fraction of incident positrons
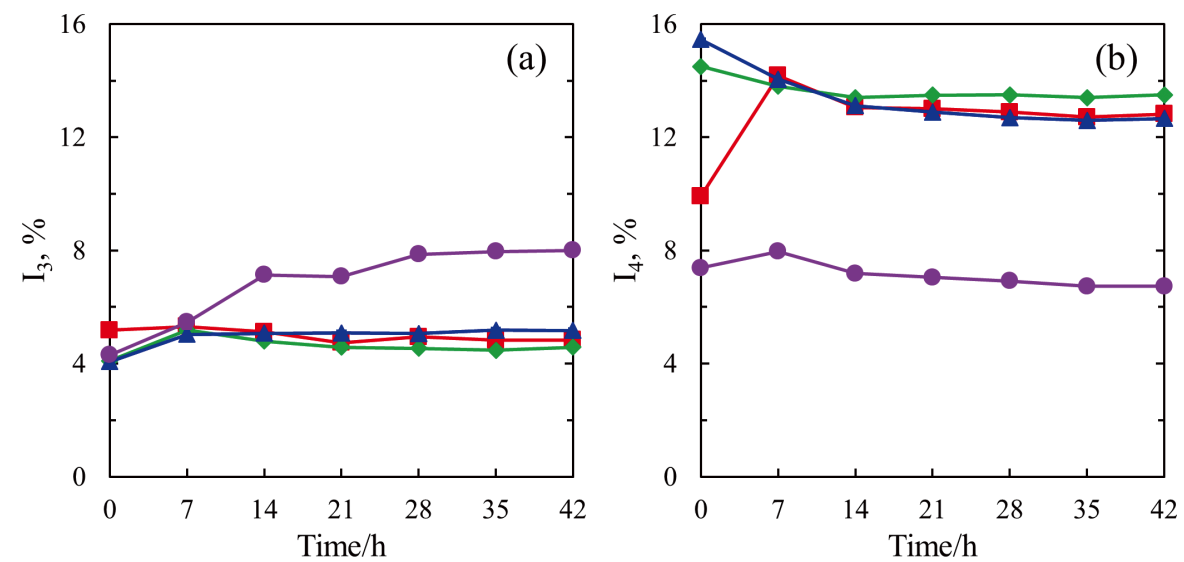

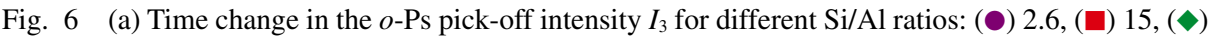
30, (ム) 40. Time 0 corresponds to the dehydrated state and thereafter the time elapsed since the exposure to the atmospheric moisture. (b) Same as (a) but for the intensity $I_{4}$ of the longest $o$-Ps component. 
that can become trapped at those sites decreases, raising the probability that they form Ps instead. In addition, the physisorption of water molecules considerably reduces the Ps oxidizing effect of those acid sites, thus leading to a greater fraction of Ps self-annihilation. The important contribution of this latter effect is manifested by the biggest net rise of $\sim 3.5 \%$ in the Ps intensity upon water adsorption observed in the sample containing the largest amount of adsorbed water $(\mathrm{Si} / \mathrm{Al}$ ratio $=$ 2.6). The total $o$-Ps intensity in all samples becomes flat after $14 \mathrm{~h}$ or so due to water saturation, as observed also in the time variation of $\tau_{3}$. The breakdown of the total $o$-Ps intensity into the intensities of the third $\left(I_{3}\right)$ and fourth $\left(I_{4}\right)$ components changing over time during the water adsorption is exhibited in Fig. 6. From these results it is understood that the $\mathrm{Si} / \mathrm{Al}$ dependence of the total $o$-Ps formation ratio observed in the dehydrated state (Fig. 3) principally stems from the fourth component, because virtually no difference in $I_{3}$ is detected between the various samples.

Both changes in Ps lifetime and intensity upon water adsorption show a clear distinction in the chemical activity between zeolites with a $\mathrm{Si} / \mathrm{Al}$ ratio $\leq 15$ and those with a ratio higher than that value. The difference in behavior between lowsilica and high-silica zeolites is well known and is related to the increase in concentration of acid sites but a concomitant decrease in their activity (depending on the density of the framework), for zeolites with higher Al contents. ${ }^{65}$ Specifically, the discrepancy observed in Fig. 5 under the influence of water can be ascribed to the strong affinity of low-silica zeolites to adsorb a large amount of water molecules in their pores and channels, which has a critical influence on the adsorptive and catalytic properties. ${ }^{34}$ The adsorption and desorption of water molecules inside the zeolite framework induces the displacement of cations and changes the distribution of electron density of the crystalline backbone structure. ${ }^{66,67}$ In turn, these competing active sites are expected to more greatly affect the Ps formation probability in low-silica rather than high-silica zeolites.

\section{Conclusions}

In this study, we investigated the correlation between the $o$-Ps behavior and the chemical state in the pores of Y-type zeolites with varying $\mathrm{Si} / \mathrm{Al}$ ratios. Positron lifetime measurements showed that, in the dehydrated state, the Ps pick-off lifetime and the Ps formation ratio decreased as the $\mathrm{Al}$ content in the zeolite increased (smaller $\mathrm{Si} / \mathrm{Al}$ ratio). This was thought to be related to the larger number of Brønsted acid sites present in the pores when the Si/Al ratio becomes smaller. The Ps lifetime was reduced due to the increased Ps pick-off annihilation rate at these negatively-charged centers. Larger positron trapping and Ps oxidation at these acid sites were found to reduce the Ps intensity. After water adsorption in the micropore network, a net rise in the Ps formation ratio was seen in the hydrophilic low-silica samples. This was understood as the effect of water molecules binding to the Brønsted acid sites and rendering them inactive. As positrons could no longer become trapped at those sites and their Ps oxidizing action was suppressed, the Ps formation and annihilation probability was enhanced. The present study confirmed that Ps may be used as a sensitive probe of the chemical state in the micropore structure of the zeolites and that its behavior can be used to characterize acidity effects under different environments. Future work to interpret the impact of the concentration of Brønsted acid sites on the Ps behavior and extending these findings to other framework types might be very valuable.

\section{Acknowledgements}

This work was partially supported by JSPS KAKENHI grants no. $18 \mathrm{~K} 13980$ and no. $19 \mathrm{H} 02742$. The authors would like to acknowledge H. Noguchi's assistance in the preparation of the manuscript.

\section{References}

1. J. Čejka, R. E. Morris, and P. Nachtigall, "Zeolites in Catalysis: Properties and Applications", ed. J. Čejka, R. E. Morris, and P. Nachtigall, 2017, Royal Society of Chemistry, London.

2. Y. Li, L. Li, and J. Yu, Chem, 2017, 3, 928.

3. J. Čejka, A. Corma, and S. Zones (ed.), "Zeolites and catalysis: Synthesis, Reactions and Applications", 2010, WILEY-VCH Verlag, Weinheim.

4. S. M. Auerbach, K. A. Carrado, and P. K. Dutta, "Handbook of Zeolite Science and Technology", ed. S. M. Auerbach, K. A. Carrado, and P. K. Dutta, 2003, Marcel Dekker, New York, Basel.

5. Y. C. Jean, P. E. Mallon, and D. M. Schrader, "Principles and Applications of Positron and Positronium Chemistry", 2003, World Scientific, Singapore.

6. Y. Kobayashi, K. Ito, T. Oka, and K. Hirata, Radiat. Phys. Chem., 2007, 76, 224.

7. Y. Sasaki, Y. Nagai, H. Ohkubo, K. Inoue, Z. Tang, and M. Hasegawa, Radiat. Phys. Chem., 2003, 68, 569.

8. M. Ono, K. Hara, M. Fujinami, and S. Ito, Appl. Phys. Lett., 2012, 101, 164103.

9. J. Kansy, G. Consolati, and C. Dauwe, Radiat. Phys. Chem., 2000, 58, 427.

10. Y. Ito, H. F. M. Mohamed, V. P. Shantarovich, and T. Suzuki, Membrane, 2009, 34, 164.

11. Y. Ito, T. Takano, and M. Hasegawa, Appl. Phys. A: Mater. Sci. Process, 1988, 45, 193.

12. H. Nakanishi and Y. Ujihira, J. Phys. Chem., 1982, 86, 4446.

13. A. Zubiaga, R. Warringham, S. Mitchell, L. Gerchow, D. Cooke, P. Crivelli, and J. Pérez-Ramírez, ChemPhysChem, 2017, 18, 470.

14. G. Dlubek, H. M. Fretwell, and M. A. Alam, Macromolecules, 2000, 33, 187.

15. V. P. Shantarovich, T. Suzuki, C. He, and V. W. Gustov, Radiat. Phys. Chem., 2003, 67, 15.

16. F. C. Oliveira, A. M. Oliveira, C. L. Donnici, J. C. MacHado, W. F. Magalhães, D. Windmöller, F. H. Fulgêncio, and L. R. Souza, Chem. Phys. Lett., 2011, 506, 37.

17. J. Datka and E. Tuznik, J. Catal., 1986, 102, 43.

18. B. L. Su and V. Norberg, Zeolites, 1997, 19, 65.

19. N. Katada, K. Suzuki, T. Noda, G. Sastre, and M. Niwa, J. Phys. Chem. C, 2009, 113, 19208.

20. S. P. Greatbanks, I. H. Hillier, N. A. Burton, and P. Sherwood, J. Chem. Phys., 1996, 105, 3770.

21. L. Grajciar, C. O. Areán, A. Pulido, and P. Nachtigall, Phys. Chem. Chem. Phys., 2010, 12, 1497.

22. W. Zhang and P. G. Smirniotis, J. Catal., 1999, 182, 400.

23. G. H. Kuehl and H. K. C. Timken, Microporous Mesoporous Mater, 2000, 35, 521.

24. A. J. Jones, R. T. Carr, S. I. Zones, and E. Iglesia, J. Catal., 2014, 312, 58.

25. S. Schallmoser, T. Ikuno, M. F. Wagenhofer, R. Kolvenbach, 
G. L. Haller, M. Sanchez-Sanchez, and J. A. Lercher, J. Catal., 2014, 316, 93.

26. R. A. Beyerlein, C. Choi-Feng, J. B. Hall, B. J. Huggins, and G. J. Ray, Top. Catal., 1997, 4, 27.

27. B. Xu, S. Bordiga, R. Prins, and J. A. van Bokhoven, Appl. Catal., A, 2007, 333, 245.

28. B. Xu, C. Sievers, S. B. Hong, R. Prins, and J. A. van Bokhoven, J. Catal., 2006, 244, 163.

29. A. Galarneau, D. Mehlhorn, F. Guenneau, B. Coasne, F Villemot, D. Minoux, C. Aquino, and J.-P. Dath, Langmuir, 2018, 34, 14134 .

30. S. C. Larsen, J. Phys. Chem. C, 2007, 111, 18464.

31. D. Yuan, D. He, S. Xu, Z. Song, M. Zhang, Y. Wei, Y. He, $\mathrm{S}$. Xu, Z. Liu, and Y. Xu, Microporous Mesoporous Mater. 2015, 204, 1 .

32. R. Cid, F. J. G. Llambías, J. L. G. Fierro, A. L. Agudo, and J. Vlllaseñor, J. Catal., 1984, 89, 478 .

33. Z. Shu, T. Li, J. Zhou, Y. Chen, Z. Sheng, Y. Wang, and X. Yuan, Appl. Clay Sci., 2016, 123, 76.

34. S. Bosnar, D. Bosnar, N. Ren, N. Rajić, B. Gržeta, and B. Subotić, J. Porous Mater., 2013, 20, 1329.

35. N. Wang, M. Zhang, and Y. Yu, Microporous Mesoporous Mater, 2013, 169, 47

36. R. Zhao, Z. Zhao, S. Li, and W. Zhang, J. Phys. Chem. Lett., 2017, 8, 2323.

37. W. Zhang, X. Han, X. Liu, H. Lei, X. Liu, and X. Bao, Microporous Mesoporous Mater., 2002, 53, 145.

38. J. Jiao, J. Kanellopoulos, W. Wang, S. S. Ray, H. Foerster, D. Freude, and M. Hunger, Phys. Chem. Chem. Phys., 2005, 7, 3221

39. T. Noda, K. Suzuki, N. Katada, and M. Niwa, J. Catal., 2008, 259, 203.

40. C. S. Triantafillidis, A. G. Vlessidis, and N. P. Evmiridis, Ind. Eng. Chem. Res., 2000, 39, 307.

41. L. Chiari and M. Fujinami, "Handbook of Advanced NonDestructive Evaluation", ed. N. Ida and M. Norbert, 2019, Springer International Publishing, Cham, 1301.

42. V. I. Goldanskii, B. M. Levin, A. D. Mokrushin, M. A. Kaliko, and M. N. Pervushina, Dokl. Akad. Nauk SSSR, 1970, 191, 855.

43. V. I. Goldanskii, B. M. Levin, V. A. Pazdzerskij, and V. P. Shantarovich, Dokl. Akad. Nauk SSSR, 1976, 228, 1372.

44. W. F. Huang, K. J. Hung, and D. C. Huang, Mater. Sci. Forum, 2001, 363-365, 263.

45. B. M. Levin, V. P. Shantarovich, D. A. Agievskii, M. V. Landau, and G. D. Chukin, Kinet. Katal., 1977, 18, 1542.
46. Z. Gao, X. Yang, J. Cui, and Y. Wang, Zeolites, 1991, 11, 607.

47. W. F. Huang, R. Ochoa, and R. Miranda, Phys. Lett. A, 1991, 158, 417.

48. A. A. Paiziev, in "Radiation Physics and Chemistry", 2000, Elsevier Science Ltd, 787 - 790.

49. W. F. Huang, D. C. Huang, and P. K. Tseng, Catal. Lett., 1994, 26, 269.

50. W. F. Huang, D. C. Huang, K. J. Hung, and P. K. Tseng, Catal. Lett., 1996, 40, 31.

51. A. Zubiaga, R. Warringham, M. Boltz, D. Cooke, P. Crivelli, D. Gidley, J. Pérez-Ramírez, and S. Mitchell, Phys. Chem. Chem. Phys., 2016, 18, 9211.

52. W. F. Huang, K. J. Hung, D. C. Huang, C. C. Huang, and P. K. Tseng, Catal. Lett., 1999, 59, 213.

53. R. Warringham, L. Gerchow, D. Cooke, P. Crivelli, R. S. Vallery, S. Mitchell, and J. Pérez-Ramírez, J. Phys. Chem $C, \mathbf{2 0 1 8}, 122,3443$

54. W. F. Huang, K. J. Hung, D. C. Huang, C. C. Huang, and P. K. Tseng, Phys. Lett. A, 2000, 266, 430.

55. J. V. Olsen, P. Kirkegaard, N. J. Pedersen, and M. Eldrup, Phys. Status Solidi C, 2007, 4, 4004.

56. Z. Kajcsos, G. Duplâtre, L. Liszkay, I. Billard, A Bonnenfant, E. Azenha, K. Lázár, G. Pál-Borbély, P. Caullet, J. Patarin, and L. Lohonyai, Radiat. Phys. Chem., 2000, 58, 709 .

57. M. Eldrup, D. Lightbody, and J. N. Sherwood, Chem. Phys., 1981, 63, 51.

58. S. J. Tao, J. Chem. Phys., 1972, 56, 5499

59. T. Crémoux, I. Batonneau-Gener, A. Moissette, J. L. Paillaud, M. Hureau, E. Ligner, C. Morais, S. Laforge, C. Marichal, and H. Nouali, Phys. Chem. Chem. Phys., 2019, $21,14892$.

60. O. E. Mogensen, J. Chem. Phys., 1974, 60, 998.

61. V. M. Byakov, Int. J. Radiat. Phys. Chem., 1976, 8, 283.

62. O. E. Mogensen, "Positron Annihilation in Chemistry", ed O. E. Mogensen, 1995, Springer-Verlag, Berlin, Heidelberg.

63. K. Sato, K. Fujimoto, K. Kawamura, W. Dai, and M. Hunger, J. Phys. Chem. C, 2012, 116, 22954.

64. S. Y. Chuang and S. J. Tao, J. Chem. Phys., 1971, 54, 4896.

65. J. Dědečk, Z. Sobalík, and B. Wichterlová, Catal. Rev. 2012, 54, 135.

66. C. E. A. Kirschhock, B. Hunger, J. Martens, and P. A. Jacobs, J. Phys. Chem. B, 2000, 104, 439.

67. T. Ohgushi and Y. Sakai, J. Phys. Chem. C, 2007, 111, 2116. 